Volume: 14 Issue: 1 Year: 2017

\title{
Self-reports of sexual attraction change in a sample of male psychotherapy consumers in a private practice setting
}

\author{
James Edward Phelan ${ }^{1}$
}

\begin{abstract}
The purpose of this study was to see if clients in a private practice therapy setting reported any changes in how they rated their sexual attraction, their stated goal. The therapy was conducted weekly, lasting at least one year. The sample was comprised of 30 men whose desired goal was toward a shift from same-sex attraction to opposite-sex attraction. A convenience sample from the author's private practice, over a 5-year span, was used. Clients were invited to complete surveys at intake, between 12-18 months into therapy, and one year afterwards. Following the format of the Klein Sexual Orientation Grid, clients were asked about sexual attraction on a measurable continuum. A repeated-measures analysis of variance (ANOVA) was used to test the differences between the pre, mid, and post responses. In this sample, at 1 year post-discharge, $10 \%$ reported their sexual attraction as "for the other sex somewhat" vs. $0 \%$ at baseline; $17 \%$ reported their sexual attraction as "for the other sex mostly" vs. $0 \%$ at baseline; and $23 \%$ reported their sexual attraction was "for the other sex only" vs. $0 \%$ at baseline. These outcomes proved statistically significant changes from baseline compared to follow up. Despite the study's limitations, significant sexual attraction shifts from same-sex to opposite-sex were self-reported in a highly motivated clinical sample of men.
\end{abstract}

Keywords: Sexual orientation treatment efforts (SOCE); sexual attraction; same-sex attraction; opposite-sex attraction; sexual attraction change; conversion therapy; reparative therapy; Kinsey Scale; Klein Sexual Orientation Grid.

\section{Introduction}

Sexual orientation behaviors and psychological changes have been historically documented in the classic psychoanalytic literature, yet criticized for being reported in ways that lack methodological rigor (APA, 2009). For example, in a psychoanalytic case, Gordon (1930) described an outcome of a male patient, who said at the beginning of treatment that, "heterosexuality was repugnant to him [and] there was not even the least desire to seek companionship of females" (p. 154). The patient had same-sex desires and had acted on them on occasion. After completing psychoanalytic therapy the patient made "no attempt on his part to look for an opportunity of returning to [homosexual] behavior" (p. 155). Eventually, the patient met a woman and "he became undeniably heterosexual," and "an aversion for homosexuality rapidly developed" (p. 155). He finally married and "...no reference was made by him on his former [homosexual] condition" (p. 155). Although the duration of treatment was not specified, it was assumed to be long-term since Gordon mentioned he started work with the patient during the patient's time in medical school and continued working with him long distance during his 18-month internship, up until he became a full-pledged physician. He mentioned following up with him, "once or twice a year" ( $p$ 155), and

1 James E. Phelan, Phelan Consultants, LLC, Columbus, OH, USA (Formerly Wilkes-Barre, PA), jpmphelan@sbcglobal.net 
Phelan, J. E. (2017). Self-reports of sexual attraction change in a sample of psychotherapy consumers. Journal of Human Sciences, 14(1), 717-723. doi:10.14687/jhs.v14i1.4282

that "the adjustment was perfect... he is now a father of two children and very happy in his domestic life" (p. 155).

Case illustrations, narratives, and other therapists' reports were customary during the late $20^{\text {th }}$ century. Any type of framework, clinical or otherwise, that has the general goal of changing a person's sexual orientation albeit identity, behaviors, psychological states, and/or relationships has recently been labeled under the umbrella term, "sexual orientation change efforts" (SOCE); the terms "conversion therapy," or "reparative therapy" are also used (APA, 2009). Serovich et al. (2008) completed a systemic literature review and identified the term "sexual reorientation" as therapies using methods considered reparative (psychosocial) or aversive (behavioral). Their search yielded 182 articles, ending with 28 that were considered empirically based. They were critical of the reports, stating several limitations existed. The limitations included a lack of theory, inconsistent definition and measurement of sexual orientation, restricted samples, lack of longitudinal designs, and sex disparity.

\section{Specific consumer reports published in the new millennium}

In a study by Nicolosi, Byrd and Potts (2000) over one-third of 882 participants identified themselves as exclusively homosexual prior to any intervention, but at the time of follow-up almost $18 \%$ reported that they viewed themselves as exclusively heterosexual. Before any intervention, a little over $2 \%$ of the participants perceived themselves as exclusively or almost entirely heterosexual, whereas after intervention over one-third perceived themselves as exclusively, or almost entirely heterosexual. In all, over $45 \%$ of the participants who identified as exclusively homosexual reported having made some shifts in their sexual orientation.

Shidlo and Schroeder (2002) conducted an exploratory study based on retrospective accounts of 202 adult consumers who had received interventions in which they explicitly desired "changing [their] homosexual orientation" (p. 250). Prior to any intervention, consumers rated themselves between 5 (more homosexual than heterosexual) and 7 (exclusively homosexual) on the 7-point Kinsey Scale. Of the 26 consumers who perceived their post-intervention outcomes as "successful" (p. 253), 8 (or about 30\%) rated themselves as 3 or less on the Kinsey Scale, yielding a significant shift.

Spitzer (2003) retrospectively interviewed 143 adult men and 57 adult women consumers of SOCE. He administered a 114 closed-ended questionnaire, asking about interventions and outcomes. In terms of sexual attraction, he found that 65 or $46 \%$ of the 143 men and 24 or $42 \%$ of the 57 women reported exclusive homosexual attraction prior to intervention. After interventions, he found that 24 or $17 \%$ of the men and 31 or $54 \%$ of the women reported exclusive heterosexual attraction.

Karten and Wade (2010) examined outcomes of SOCE with 117 adult men who sought intervention for "dissatisfact[ion] with their same-sex attraction" (p. 84) using a 7-point scale, from 1 indicating exclusive homosexual attraction to 7 indicating exclusive heterosexual attraction. They found a statistically significant increase in heterosexual self-identity from the onset of intervention $(\mathrm{m}=2.57)$ to the time of study $(\mathrm{m}=4.81)$. The researchers concluded, "On average, the men in our sample reported: a decrease in homosexual feelings and behavior, an increase in heterosexual feelings and behavior, and a positive change in their psychological functioning" (p. 97).

Jones and Yarhouse (2011) conducted a naturalistic, quasi-experimental, longitudinal study spanning 6 to 7 years with adult consumers who sought religiously mediated SOCE for "sexual orientation change" (p. 409) for at least one year or more. Longitudinally followed and using the 7-

\footnotetext{
2 According to the American Heritage ${ }^{\circledR}$ Dictionary of the English Language "the Kinsey Scale is a classification system for gauging sexual orientation, designed by Alfred Kinsey" ( $0=$ exclusively heterosexual; $1=$ predominantly heterosexual, only incidentally homosexual; $2=$ predominantly heterosexual, but more than incidentally homosexual; $3=$ equally heterosexual and homosexual; $4=$ predominantly homosexual, but more than incidentally heterosexual; $5=$ predominantly homosexual, only incidentally heterosexual; $6=$ exclusively homosexual).
} 
Phelan, J. E. (2017). Self-reports of sexual attraction change in a sample of psychotherapy consumers. Journal of Human Sciences, 14(1), 717-723. doi:10.14687/jhs.v14i1.4282

point Kinsey Scale, 18 out of 61 (30\% of) consumers rated themselves as 3 or less on the Kinsey Scale, yielding a significant shift.

\section{Summary of research questions and hypotheses}

Unlike the consumer studies above, conducted by researchers interested in outcomes for collective reporting purposes, the current study was unique and conducted to track clients' progress and to report outcomes in an independent setting by the therapeutic provider. The study set out to answer the research question: Do clients' with specific intake goals show significant changes at midpoints and post-discharge? Based on what is already known about sexual orientation fluidity from past research, coupled with the knowledge base that client motivation generally creates desired outcomes, it was hypothesized that clients' with specific intake goals in a private practice setting would produce desired outcomes regardless of technique (Rosenzweig, 1936).

\section{Participants}

\section{Materials and Methods}

All participants were adult men who were referred to the author for psychotherapy during a 5-year span. Participants' anonymity was assured and participation was voluntary and noncompensated. The study was independent, non-funded, and non-institutional, therefore an institutional review board process was not applicable. Prior to therapy, clients who rated their sexual attractions as same sex only, same sex mostly, or same sex somewhat, were invited to complete surveys between 12-18 months into therapy, and one year afterwards, and served as this study's overall sample $(N=30)$. The sample was a convenience sample of consumers' self-reports. Participants were informed that participant was voluntary and that their identities would be kept confidential. Participants were able to opt out at any time.

The majority of participants were white $(90 \%)$ and had a college degree $(56 \%)$, or had some college education (26\%). Most were single, never married (90\%). Most were USA citizens (90\%). As far as religious affiliation: 1 was Buddhist, 1 Hindu, 1 Jewish, 1 Episcopalian, 2 agnostics, 2 Mormons, 5 had no affiliation (with 2 saying they were atheists), 6 Catholics, and 11 evangelical Christian. Thirty-six percent were ages $18-27 ; 33 \%$ were in the age group $28-37 ; 16 \%$ in age group $38-47$; and 2 participants were age 47 or older.

\section{Measures}

Following the format of the Klein Sexual Orientation Grid clients were asked about their sexual attractions ("To whom are you sexually attracted?"). The scale measured attraction along the following measurable continuum: $0=$ other sex only; $1=$ other sex mostly; $2=$ other sex somewhat; $3=$ both sexes equally; $4=$ same sex somewhat; $5=$ same sex mostly; and $6=$ same sex only. Klein, Sepekoff, and Wolf (1985) theorized that a person's sexual orientation could change throughout their lifetime, and that no one set of sexual behaviors was sufficient to identify a person's sexual orientation. Sexual behaviors were seen as only one component, along with others such as attraction, thoughts, fantasies and affective responses.

\section{Procedure}

Prior to therapy, clients who rated their sexual attractions as same sex only, same sex mostly, or same sex somewhat, and who desired a sexual attraction shift from same-sex to opposite-sex were invited to complete surveys between 12-18 months into therapy, and one year afterwards. Clients who met these criteria were asked to complete the survey questionnaire as well as a treatment plan update at those given intervals. Tracking the therapy progress and outcomes from the start and midpoints was done as it allowed the client and the therapist to either continue what was helping, or to make changes to what was not. 


\section{Therapy}

Therapy was conducted either telephonically or in-person at least twice monthly in a

private, fee-for-service setting. In most cases, the course of therapy was conducted weekly. The course of therapy lasted at least one year. The objectives were defined by the client, and were to establish, or increase attraction to the opposite sex. Specific outcomes were not promised. Consents, limitations, and risks and benefits were discussed prior to start. Theoretical foundation was based on sexuality fluidity theory and brain plasticity theory. The former is the belief that human sexuality is not necessarily binary, and as Kinsey had postulated, can move along a continuum (Kinsey, Pomeroy, \& Martin, 1948). The latter is the belief that brain functions are not necessarily fixed and can be changed (Doidge, 2007). Self-determination theory was overarching to the therapeutic process, particularly related to the clients' needs for autonomy. Clients' ability to choose options increases their intrinsic motivation and subsequence change processes (Deci \& Ryan, 2002).

Etiological factors were not a major emphasis of therapy considering various findings argue against any single explanation for sexual attraction. If a client had assigned an etiological theory to their same-sex attraction, they were encouraged to not let that be seen as a barrier to their stated objective. Integrative techniques were used and worked as a unifying approach that brought together affective, cognitive, contextual and behavioral systems, creating a multi-dimensional relational framework (Gilbert \& Orlans, 2011).

\section{Data Analysis}

A repeated-measures analysis of variance (ANOVA) was used to test the differences between the pre, mid, and post responses.

\section{Results}

In this sample, at midpoint and 1 year after discharge, $10 \%$ of the men reported their sexual attraction was for the other sex somewhat vs. $0 \%$ at baseline; 3\% at midpoint, and $17 \%$ at 1 year follow-up reported their sexual attraction was "for the other sex mostly" vs. $0 \%$ at baseline; and 23\% reported their sexual attraction was "for the other sex only" vs. $0 \%$ at baseline (Table 1). Prior to therapy 12 men, or $40 \%$ of the sample, reported they were attracted to the same sex only; at postfollow up however, only one man reported exclusive same-sex attraction (see Table 1).

The repeated-measures analysis of variance (ANOVA) used to test the differences between the pre, mid, and post responses resulted in: $F(2,28)=82.679, p<.001, \eta_{\mathrm{p}}{ }^{2}=0.767$. The changes were statistically significant compared to the baseline: Pre to Mid, $t=-10.25, p<.001$; Pre to Post, $t$ $=-9.68, p<.001 ;$ Mid to Post, $t=-6.49, p<.001$. 
Table 1. Summary statistics

\begin{tabular}{|ccccc|}
\hline $\begin{array}{c}\text { Measurement } \\
\text { Pre }\end{array}$ & $n$ & $\%$ & Cumulative $n$ & Cumulative $\%$ \\
0 & - & - & - & - \\
1 & - & - & - & - \\
2 & - & - & - & - \\
3 & - & - & - & - \\
4 & 4 & 13.33 & 4 & 13.33 \\
5 & 14 & 46.67 & 18 & 60.00 \\
6 & 12 & 40.00 & 30 & 100 \\
Mid & & & & \\
0 & - & - & - & - \\
1 & 1 & 3.33 & 1 & 3.33 \\
2 & 3 & 10.00 & 4 & 13.33 \\
3 & 10 & 33.33 & 14 & 46.67 \\
4 & 8 & 26.67 & 22 & 73.33 \\
5 & 7 & 23.33 & 29 & 96.67 \\
6 & 1 & 3.33 & 30 & 100 \\
Post & & & & \\
0 & 7 & 23.33 & 7 & 23.33 \\
1 & 5 & 16.67 & 12 & 40.00 \\
2 & 3 & 10.00 & 15 & 50.00 \\
3 & 6 & 20.00 & 21 & 70.00 \\
4 & 5 & 16.67 & 26 & 86.67 \\
5 & 3 & 10.00 & 29 & 96.67 \\
6 & 1 & 3.33 & 30 & 100 \\
\hline
\end{tabular}

*Note. Respondents rated their attraction on the scale: 0, other sex only; 1, other sex mostly; 2, other sex somewhat; 3 , both sexes equally; 4 , same sex somewhat; 5 , same sex mostly; 6 , same sex only.

\section{Discussion}

Unlike previous consumer studies, conducted by researchers interested in outcomes for collective reporting purposes, the current study is unique and was conducted to track clients' progress and to report outcomes in an independent setting by the therapeutic provider. In the current study, sexual attraction shifts from same-sex to opposite-sex were reported, at least in a highly motivated convenience sample with men who had such outcome as their originally stated goal, supporting the original hypothesis. The demographics for this population were predominately white, educated men, who were largely under the age of 47 . Religion affiliation was high among the sample; however 23\% reported being agonistic or no religious affiliation at all. Although the APA Task Force report criticized SOCE studies as relying, "almost exclusively individuals who [had] strong religious beliefs" (APA, 2009, p. 25), in examining published studies from 1954 to 2004, 17 of which the Task Force reviewed, $82 \%$ failed to report the religion of participants (Serovich et al., 2008).

Like previous research looking at consumer reports, this study supports sexual attraction shifts. Research on sexual minorities has long documented that many report having undergone notable shifts in their patterns of sexual attractions over time (Diamond, 2009).

\section{Relevance to practice}

Tracking clients' goals from the start, midpoints, and at least one-year follow up can help trace progress. This research can help practitioners understand that clients' beliefs about their attractions are not necessarily fixed. Finally, clients have the ability to create change in a selfdeterministic way that creates a process for how they define it (Deci \& Ryan, 2002). 


\section{Limitations and needs of future research}

This study is limited in that the clients were a highly motivated, selected group who had preconceived desired outcomes. The study is limited in that it was a convenience sample and therefore not necessarily indicative of a general randomized sample. Although a big strength of the study was that an initial, mid and post-tests were given, the metric used was a self-reported question. It is not known to what extent psychotherapy played in these outcomes considering variance coupled with the fact that other people can have spontaneous change, regardless (Dickson, Paul, \& Herbison, 2003; Kinnish, Stassberg, \& Turner, 2005). Future improvements to research would be to use randomization, multi-site comparisons, expanded demographic information, and larger samples. In addition, future research can improve on defining and operationalizing the various components of sexual orientation and the scales for measuring such (Sell, 1997; Sell, n.d.).

\section{References}

American Psychological Association (APA) Task Force on Appropriate Therapeutic Responses to Sexual Orientation. (2009). Report of the Task Force on Appropriate Therapeutic Responses to Sexual Orientation. Washington, DC: Author.

Deci, E., \& Ryan, R. (Eds.). (2002). Handbook of self-determination research. Rochester, NY: University of Rochester Press.

Diamond, L. M. (2009). Sexual fluidity. Cambridge, MA: Harvard University Press.

Diamond, L. M. (2014). Gender and same-sex sexuality. In D. Tolman, \& L. Diamond, (Eds). APA Handbook of Sexuality and Psychology, Volume 1. Person Based Approaches (pp 629-652). Washington, DC: American Psychological Association.

Dickson, N., Paul, C., \& Herbison, P. (2003). Same-sex attraction in a birth cohort: prevalence and persistence in early adulthood. Social Science Medicine, 56(8),1607-15. doi: 10.1016/S02779536(02)00161-2

Doidge, N. (2007). The brain that changes itself. New York: Penguin.

Gilbert, M, \& Orlans, V. (2011). Integrative therapy. New York: Routledge.

Gordon, A. (1930). The history of a homosexual: His difficulties and triumphs. Medical Journal and Record, 131, 152-156.

Jones, S. L., \& Yarhouse, M. A. (2011). A longitudinal study of attempted religiously mediated sexual orientation change. Journal of Sex and Martial Therapy, 37, 404-427. doi: 10.1080/0092623X.2011.607052

Karten, E. L., \& Wade, J. C. (2010). Sexual orientation change efforts in men: A client perspective. Journal of Men's Studies, 18, 84-102. doi: 10.3149/jms.1801.84

Kinnish, K. K., Strassberg, D. S., \& Turner, C. W. (2005). Sex differences in the flexibility of sexual orientation: a multidimensional retrospective assessment. Archives of Sexual Behavior, 34(2),173-83. doi: 10.1007/s10508-005-1795-9

Kinsey, A. C., Pomeroy, W. B., \& Martin, C. E. (1948). Sexual behavior in the human male. Philadelphia: W.B. Saunders.

Klein, F., Sepekoff, B., \& Wolf, T. J. (1985). Sexual orientation: A multi-variable dynamic process. Journal of Homosexuality, 11(1-2), 35-49. doi: 10.1300/J082v11n01_04

Nicolosi, J., Byrd, A. D., \& Potts, R. W. (2000). Retrospective self-reports of changes in homosexual orientation: A consumer survey of conversion therapy clients. Psychological Reports, 86(3), 1071-1088. doi: 10.2466/pr0.2000.86.3c.1071

Rosenzweig, S. (1936). Some implicit common factors in diverse methods of psychotherapy. American Journal of Orthopsychiatry, 6, 412-415.

Sell, R. L. (1997). Defining and measuring sexual orientation: A review. Archives of Sexual Behavior,26(6), 643-658. doi: 10.1023/A:1024528427013

Sell, R.L. (n.d.). LGBTData.com (Program for Lesbian, Gay, Bisexual and Transgender Health, Drexel University School of Public Health). Retrieved from: http://www.lgbtdata.com 
Serovich J. M., Craft, S. M, Toviessi, P., Gangamma, R., McDowell, T., \& Grafsky, E. L. (2008). A systematic review of the research base on sexual reorientation therapies. Journal of Marital and Family Therapy, 34(2), 227-38. doi: 10.1111/j.1752-0606.2008.00065.x.

Shidlo, A., \& Schroeder, M. (2002). Changing sexual orientation: A consumer's report. Professional Psychology: Research and Practice, 33(3), 249-259. doi 10.1037/0735-7028.33.3.249

Spitzer, R. L. (2003). Can some gay men and lesbians change their sexual orientation? 200 participants reporting a change from homosexual to heterosexual orientation. Archives of Sexual Behavior, 32(5), 403-417. doi: 0004-0002/03/1000-0403/0 